\title{
A BONE FLUID FLOW HYPOTHESIS FOR MUSCLE PUMP-DRIVEN CAPILLARY FILTRATION: II PROPOSED ROLE FOR EXERCISE IN ERODIBLE SCAFFOLD IMPLANT INCORPORATION
}

\author{
H. Winet* \\ Departments of Orthopaedic Surgery and Biomedical Engineering \\ Orthopaedic Hospital of Los Angeles, University of California at Los Angeles \\ Los Angeles, USA
}

\begin{abstract}
A model is presented for enhancement of fluid flow through bone matrix and any porous tissue engineering scaffold implanted within it. The mechanism of enhancement is the skeletal muscle pump in compartments adjacent to the bone. Pressure waves from muscle pump contractions aided by increased blood pressure during exercise coupled with temporary occlusion of arteries leading to and veins from the bone, increase hydraulic pressure in cortical bone capillaries so as to amplify capillary filtration. It is proposed that capillary filtration increase is sufficiently convective to contribute to bone fluid flow and associated percolation through tissue engineered scaffold matrix implants. Importance of this contribution is its relative role in maintaining seeded cells in bioreactor scaffolds. Validation of the hypothesis starts at a minimum level of demonstrating that capillary filtration is convective. At a maximum level confirmation of the hypothesis requires demonstration that capillary filtration-based interstitial flow is sufficient to stimulate not only host bone cells (as proposed in part I of the hypothesis) but bioreactor-seeded cells as well. Preliminary data is presented supporting the prediction that skeletal muscle contraction generates convective capillary filtration.
\end{abstract}

Key Words: Blood pressure, bone cells, bone chamber, bone fluid flow, capillary filtration, cortical bone, exercise, intravital microscopy, muscle pump, tissue engineering.

*Address for correspondence:

H. Winet

UCLA/Orthopaedic Hospital

2400 Flower St.

Los Angeles, CA 90007, USA

FAX Number: 213-742-1515

E-mail: hwinet@laoh.ucla.edu
Introduction

Tissue engineered scaffolds require vascularization to (1) enhance nutrient exchange and (2) provide cells needed to build new tissue. Cell-seeded scaffolds - bioreactorsrequire rapid penetration of vessels or enhanced fluid percolation to keep their contents alive until normal nutrient exchange can be established. Accordingly, scaffolds implanted in bone for purposes of stimulating osteogenesis must be at least angio- and osteo-conductive. The ultimate scaffold will be angio- and osteo-inductive as well. Growth factors/polypeptide cytokines are usually employed as growth inducers. They are ineffective, however, if their release rate is not controlled to match the state of "readiness" of target cells. Accordingly, transport must be coordinated.

Nutrient exchange is not the sole function of transport in bone. There is increasing evidence that interstitial fluid flow is sensed by and modulates the behavior of bone cells. Percolation through bone matrix and associated implants is referred to as bone interstitial fluid flow (BIFF). Two mechanisms for bone cell sensing of BIFF have been proposed; one mechanical and the other electrokinetic. The electrokinetic model focuses on streaming potentials that are putatively sensed by electrokinetic receptors in bone cell membranes. The mechanical model focuses on shear stress at the membrane-fluid interface, which is transmitted to second messenger by mechano-receptors.

Each model takes advantage of the observation that volume fraction of water in cortical bone water is $13 \%$ (Morris et al., 1982) and molecules at least as large as ferritin percolate through the matrix via solvent drag from osteon to osteon at rates well in excess of diffusion (Dillaman, 1984; Li et al., 1987; Montgomery et al., 1988; Dillaman et al., 1991; Kelly and Bronk, 1994; Knothe Tate and Knothe, 2000). The electrokinetic model was developed in 1968 by Anderson and Eriksson (1968) who proposed that flowing ions in bone fluid established streaming potentials relative to fixed cell membrane charges. In vitro experiments have confirmed bone cell response to streaming potentials (Otter et al., 1985, 1990, 1992, 1996; Walsh and Guzelsu, 1991, 1993; MacGinitie et al., 1993, 1997; Chen et al., 1997; Pollack, 2001). In 1990 Frangos and colleagues proposed that bone cells respond to fluid shear stress in a manner similar to endothelial cells (Reich et al., 1990). Control of endothelial cell activity by blood flow-generated fluid shear stress is well established (Frangos et al., 1985). Given the high incidence of redundancy in evolved tissues and the common ancestry of the two cell types from mesenchymal 
stem cells, this response is not surprising. It has also been confirmed in vitro (Reich and Frangos, 1991; KleinNuland et al., 1995; Johnson et al., 1996; Hillsley and Frangos, 1997), but there are important differences between endothelial and bone cells. For example, osteocytes and their processes are surrounded by relatively thin fluid (not necessarily Newtonian) annuli in the lacunar and canalicular compartments, rather than relatively large volumes of flowing blood. No direct measures of fluid flow in vivo over bone cell surfaces have been obtained, but in vitro experiments indicate a shear stress stimulation threshold producing 1\% strain(Burger, 2001) and a streaming potential threshold of $10 \mathrm{mV}$ (Hung et al., 1996).

What is unclear at this point is the source of hydraulic pressure gradients required to drive BIFF. It has been proposed that BIFF is generated by incompressible fluid shifts resulting from pressure and tension cycles on interstitial fluid during bending of bone by muscle contraction and weight-bearing whether during locomotion (Piekarski and Munro, 1977; Weinbaum et al., 1994; Knothe Tate et al., 1998; Srinivasan and Gross, 2000; Steck et al., 2000; Cowin, 2001a; Knothe Tate, 2001; Petrov and Pollack, 2001; Pollack, 2001; Prendergast and van der Meulen, 2001) or posture maintenance (Fritton et al., 2000; Rubin et al., 2001). The basis for the current model is Biot's poroelasticity theory (Biot, 1955) which predicts fluid percolation rates based on pore geometry and distribution coupled with matrix elasticity (Cowin, 1999, 2001a). There have been tissue-level observations supporting the general concept of the model (Montgomery et al., 1988; Turner et al., 1994; Knothe Tate et al., 1998, 2000), and initial bone bending-based model calculations predicting fluid shear stress on in vivo osteocytes indicated that it reaches magnitudes sufficient to cause the required $1 \%$ strain. However, more recent model refinements with real measures indicate that flow rates generated by poroelastic bending alone (i.e. disregarding weight loading) is not sufficient to reach this threshold (Keanini et al., 1995; Cowin, 2001b; Petrov and Pollack, 2001).

Published reports modeling flow generated by bone bending either (1) state that flow in capillaries driven by heartbeat alone generates capillary filtration rates too small to exceed activation threshold shear stress of osteocytes, or (2) simply ignore trans-capillary pressure gradients (Piekarski and Munro, 1977; Weinbaum et al., 1994; Knothe Tate et al., 1998; Srinivasan and Gross, 2000; Steck et al., 2000; Cowin, 2001a; Knothe Tate, 2001; Petrov and Pollack, 2001; Pollack, 2001; Prendergast and van der Meulen, 2001). McCarthy and Yang (1992) have criticized this limitation of a pressure generating mechanism to poroelasticity. Hillsley and Frangos (1994) suggested that capillary filtration is an important source of the BIFF which stimulates bone cells by fluid shear stress. In addition, they proposed that cytokines, such as NO, which are secreted by endothelial cells and affect osteoblasts, are enhanced in transport by capillary filtration. Otter found that streaming potential signals correlated highly with circulation generated IMP pressure oscillations (Otter et al., 1990) that were generated in cortical bone in the absence of weight bearing and muscle contraction. No conclusions were drawn on the ability of these potentials to stimulate bone cells. The notion that capillary filtration can help drive BIFF broadens the range of mechanical factors driving percolation to include those which alter blood flow and capillary hydraulic pressure. It opens the door to consideration of effects on BIFF of changes in all factors that affect blood pressure, from emotion to exercise to microgravity.

We propose that capillary filtration under appropriate conditions contributes a significant, if not sufficient convective component to BIFF to activate host and bioreactor bone cells. The idea of enhancing BIFF by increasing capillary filtration is not new. Saphenous vein compression causes increased capillary filtration and periosteal bone formation in canine tibias (Kelly and Bronk, 1990; Bronk et al., 1993). In the proposed model muscle pump and exercise effects combine to increase capillary filtration sufficiently to add a significant component to BIFF. We reason that skeletal muscle, acting through a muscle pump mechanism, increases the rate of capillary filtration by increasing capillary hydraulic pressure via contraction of skeletal muscle in compartments adjacent to bone. Exercise magnifies the affect by increasing baseline blood pressure through increased heartrate and muscle pump activity. Two anatomical circumstances suggest how the mechanism operates: (1) bone influx and efflux vessels outside bone are contained within fasciabounded compartments, which include skeletal muscle, and (2) efflux vessels (veins) are valved. When the muscle pump contracts all vessels within its compartment are occluded. At the same time, two solitons (solitary pressure waves), one traveling upstream and one downstream are generated in the vessels' incompressible fluid. Solitons moving toward the bone are upstream in veins and downstream in arteries. Venous valves close and block capillary blood efflux (with the exception of collaterals that do not empty into the involved muscle compartment). Pressure in arteries rises and is transmitted to the nearest downstream capillary bed. If such a bed is in cortical bone, capillary filtration contribution to cortical BIFF is enhanced. Any implant in the percolation path will also experience enhanced transport.

\section{General Effects of Exercise on Microcirculation}

In order to demonstrate that microcirculation contributes directly to convective transport in any tissue, it must first be demonstrated that capillary filtration is convective. Two measures of capillary filtration commonly used are capillary filtration coefficient $P_{f}$, and hydraulic conductivity $L_{p}$. These quantities are related by the equation $P_{f}=\mathrm{S} L_{p}$ (Granger et al., 1981) where S is the permeable capillary surface area. In most cases the value of $\mathrm{S}$ is not known, so it is difficult to determine if $P_{f}$ is due to an $L_{p}$ value large enough to indicate substantial convection or to substantial vessel recruitment (Michel and Curry, 1999). Cases where convection was thought to have been demonstrated in a subject at rest (Rippe and Haraldsson, 1994) have been questioned by some who propose the result may have been an artifact of methodology (Renkin and Tucker, 1998). The consensus appears to be that in a horizontal body at rest $L_{p}$ is diffusive (Michel and Curry, 1999).

It is, however, generally accepted that $L_{p}$ is convec- 
tive when capillary pressure is sufficiently high (Sejrsen et al., 1981) and/or flow is sufficiently fast to create shear stress which will stimulate endothelial cells to increase capillary permeability (Kajimura et al., 1998), as occurs during exercise. In the latter case endothelial nitric oxide (eNO) is proposed to be a major local effector (Yuan et al., 1992). During exercise cardiac output share received by muscles rises from $15-20 \%$ to $80-90 \%$, at least five fold, controlled by local metabolic factors (Tzemos et al., 2002). The abundance of studies on the physiology of skeletal muscle microcirculation during exercise is matched only by the paucity of similar studies in bone. The pressure increase in skeletal muscle arteries is not as great as the increase in muscle perfusion. For example, gastrocnemius blood flow increased from 4.7 to $10.3 \mathrm{ml} / 100 \mathrm{ml} / \mathrm{min}$ during human rhythmic foot loading against a wall, yet corresponding blood pressure only increased from 82 to $85 \mathrm{mmHg}$ (Miller et al., 2000). In contrast pressure changes may be substantial in capillaries (of the order $18 \mathrm{mmHg}$ (Lipowsky, 1981)). Initial rise of capillary filtration driving pressure $\left(=J_{0} / P_{f}\right.$, where $J_{0}$ is flux through capillary wall) in cat sympathectomized skeletal muscle may rise to $58 \mathrm{mmHg}$ during graded exercise (Björnberg, 1990). In an "exercised" cat muscle organ preparation with the sympathetic input intact, capillary pressure rose from 16.7 to $32 \mathrm{mmHg}$ in one study (Maspers et al., 1990) and by $12.2 \mathrm{mmHg}$ in another, leading to "marked" capillary filtration (Maspers et al., 1991). With exercise and vessel dilation, increased vessel dilation and the resultant decrease in resistance and pressure observed by Maspers (Maspers et al., 1990) indicates a complex relationship in muscle blood flow. In a number of rat-on-treadmill studies skeletal muscle showed an increase in $P_{f}$ of 27\% (Sexton et al., 1988; Sexton and Laughlin, 1994; Sexton, 1995). Our inability to accurately predict microvascular response to increased perfusion during exercise may be linked to (1) hypervolemia which is delayed and may continue for at least 24 hours post exercise (Haskell et al., 1997), (2) albumin extravasation which is linked to hypervolemia and changes the transluminal oncotic pressure gradient (Haskell et al., 1997), (3) the formation of temporary shunt vessels (Slaaf and Oude Egbrink, 2002), (4) decrease in venous resistance (increase in vascular conductance)(Shoemaker et al., 1999), which in one study presented as a pressure drop of $45 \mathrm{mmHg}$ (Shiotani et al., 2002) and (5) varies from vein to vein (Neglen and Raju, 2000), and 6) neuroendocrine, autocrine, paracrine and other secreted regulatory agents which effect both permeability (Michel and Curry, 1999) and perfusion (Davies, 1995; Saltin et al., 1998) add to the complexity of BIFF.

\section{Heart and Muscle Pumps in a Normal Gravity Environment}

Gravity complicates fluid distribution. In the horizontal body blood is pumped through bone microvascular beds by baseline heartbeat. Distribution is modulated by local switching of pathways in response to tissue oxygen demand. Extravascular fluid tends to settle downward under gravity, but the vertical distances are short and oxygen is sufficiently distributed to make local anoxias insignificant. Prolongation of this condition during bed rest, however, has significant physiological effects including atrophy of muscle and osteopenia (Greenleaf, 1984; Hargens, 1994; Shoemaker et al., 1999).

When the body orients vertically, extravascular interstitial fluids shift downward and the heart must increase output to insure initial venous return to the right atrium and normal flow to the cephalic artery. If the body depends on the heart alone for upward bloodflow, gravity eventually decreases venous return and cephalic delivery, allowing blood to pool in the lower extremities, and the individual faints. Under non-exercise conditions postural activity is required to maintain body balance. It has been suggested that maintenance of postural balance by muscles produces "persistent lowmagnitude" strains, which because they are spread out over long periods of time may produce sufficient mechanical stimulus to modulate bone cells (Rubin et al., 2001). Such muscle-pump activity in limbs increases bloodflow and "milks" the vessels to return blood distribution to safe levels. In the lower extremities pumping alone would be ineffective if veins and lymphatic vessels were not valved so as to prevent backflow. In the upper extremities the consequences are easily demonstrated by increase in brachial artery pressure 25-30 $\mathrm{mmHg}$ coupled with a decrease in blood flow-even during hand-grip exercises - as the forearm is moved from below to above the heart level (Shoemaker et al., 1998, 1999).

\section{Effect of Exercise on Bone Microcirculation}

Contraction of the quadriceps muscle causes a $30 \mathrm{~mm}$ $\mathrm{Hg}$ or more rise in IMP (MacPherson and Shaw, 1961; Shim et al., 1972; Kumar et al., 1979; Bryant, 1983). A physiologically relevant peak load of $600 \mu \varepsilon$ on a turkey ulna generates an IMP of $64 \mathrm{mmHg}$ (Qin et al., 2002). However, attempts, to establish a causal relationship between IMP and cortical blood flow have not been consistently successful (Thomas et al., 1982; Bouteiller et al., 1984). Pressures have not been measured in cortical bone, but normal oscillations in vessels of canine tibia medullary canals have amplitudes of about $15 \mathrm{~mm} \mathrm{Hg}$, rising from a baseline of $25 \mathrm{~mm} \mathrm{Hg}$ (Otter et al., 1990). Bone bending caused by skeletal muscle contraction does cause interstitial pressure changes that affect cortical circulation. Specifically, bloodflow tends to increase on the tension side and decrease on the compression side of the diaphysis during physiologically relevant bending (McDonald and Pitt Ford, 1993).

Exercise appears to increase bloodflow to bone, but the results are uneven. "Exhaustive" exercise in rats increases metaphyseal bloodflow, decreases diaphyseal bloodflow and does not effect marrow bloodflow (Spodaryk and Dabrowski, 1991). Short term treadmill exercise of adult dogs increased bloodflow in soft tissue around joints, but had no effect on juxtaarticular bone (Simkin et al., 1990). Longer term treadmill exercise caused a steady increase in cortical bone bloodflow from 1.6 to $2.5 \mathrm{ml} / \mathrm{min} / 100 \mathrm{~g}$ (Tondevold and Bulow, 1983).

The effect on muscle and bone microvasculature of increased bloodflow during exercise is complicated by the fact that (1) local hematocrits and shear stress on RBCs will influence both the rheology and rate of oxy- 


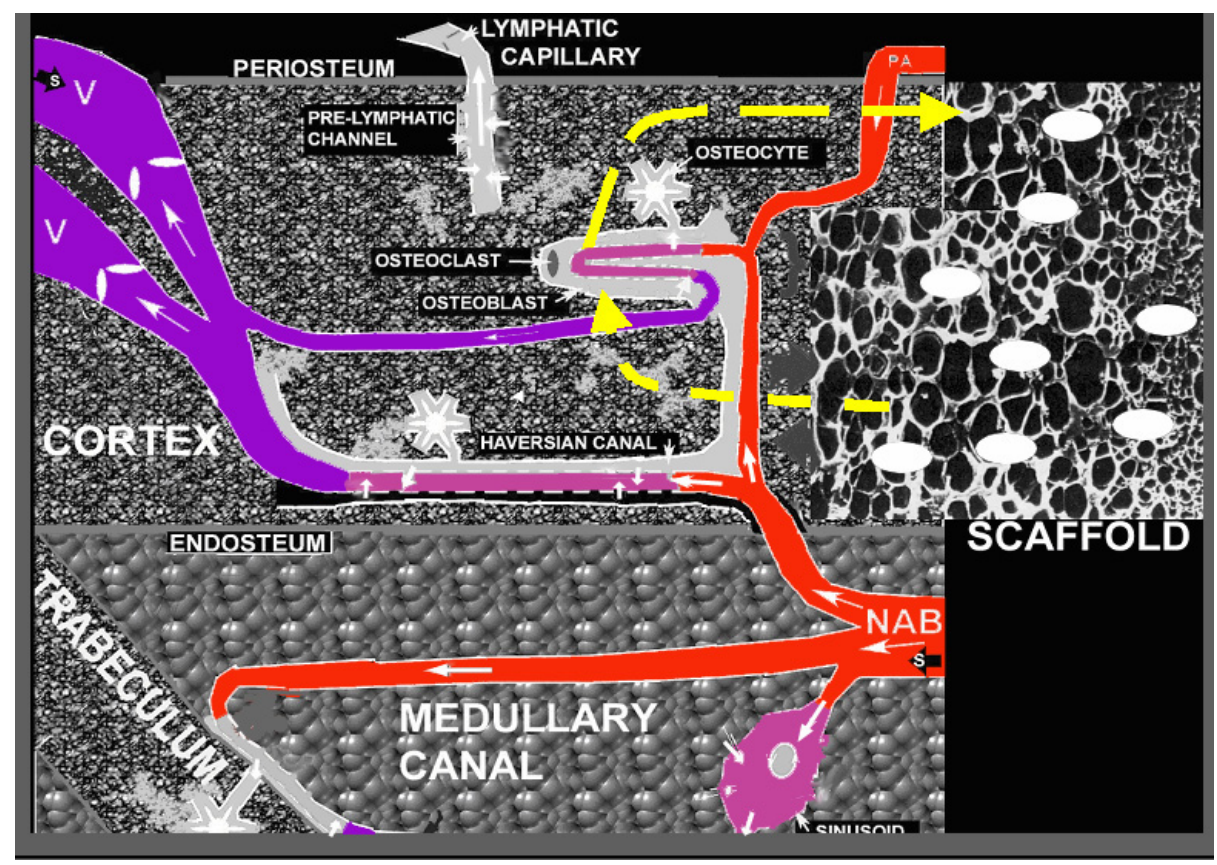

Figure 1. Cortical bone with an implanted cell-seeded bioreactor (SCAFFOLD) showing hypothetical pathways of fluid flow. Skeletal muscle is located above lymphatic capillaries in the figure. Medium and large white arrows in vessels show bloodflow. Yellow and small white arrows show extravasating and extravascular BIFF. Solitons from the skeletal muscle pump are indicated with S. Valves are shown in veins (V). Blood flows into cortex via nutrient artery branches (NAB). which branch into arterioles and capillaries of osteons and Haversian canals. Flow in capillaries is shown leading to and from an osteon which exchanges nutrients for waste from cortical bone cells and any cells in the scaffold. Fluid extravasates vasculature by capillary filtration which occurs near the arteriolar end of the capillaries. Interstitial fluid reenters vasculature by capillary absorption which occurs near the venular end of the capillaries. Interstitial fluid also exits cortical bone via pre-lymphatic channels. Enhancement of BIFF by muscle pump action enhances exchange with the bioreactor, providing nutrient support to seeded cells and increasing the rate of scaffold erosion. Muscle-caused bending and weight bearing compression/tension (dark gray arrows to left of scaffold) of the poroelastic cortical matrix probably normally dominate vascular soliton effects. During exercise, however, muscle pump and heartbeat-generated pressures should become significant contributors to BIFF.

gen delivery, (2) shear stress on endothelial cells upregulates the release of a number of agents which alter both permeability (Sill et al., 1995; Tarbell et al., 1999; Williams, 1999; Ogunrinade et al., 2002) and calibre (Pohl et al., 1986) of vessels and (3) hydrostatic pressure will rise or fall as a function of ' 2 ', increasing the potential for convective flows. It should come as no surprise that results from muscle cannot be extrapolated to bone. During the same exercise vascular resistance in bone increases two to fourfold while vasodilation in adjacent muscle increases (Gross et al., 1979).

\section{Muscle Pump Driven Bone Capillary Filtration}

Basic components of the muscle pump model for increased capillary filtration-driven BIFF are shown in Figure 1 , which is a cartoon of a longitudinal section through one cortex and adjacent medullary canal in a long bone. A skeletal muscle compartment containing vessels and bounded by fascia is at the top of the figure. Fascia has limited extensibility, a characteristic which contributes to compartment syndrome, and when skeletal muscle contracts it shortens and widens so as to compress both arteries and veins-a solid mechanics Starling resistor, as it were, which occludes the vessels. If contractions are strong, as during exercise, each one will send a soliton (s in the figure) away from the muscle belly; downstream in arteries and upstream in veins. Solitons in veins will eventually encounter valves (v), sealing off any efflux of blood from bone (except where collateral veins allow escapeone is shown in the figure). Solitons in arteries propagate to capillary beds where they increase intravascular hydraulic pressure in fluid unable to escape through veins. In any given osteon or Haversian canal capillary filtration is increased driving extravascular fluid over perivascular tissue and through nearest canaliculi. Pressures generated during exercise above heartbeat baselines can be considerable; interstitial values as high as $570 \mathrm{mmHg}$ (Sejersted et al., 1984) have been recorded. At the low end would be pressures generated during normal "postural" contractions (Fritton et al., 2000; Rubin et al., 2001). One might speculate that the muscle pump soliton threshold for generating capillary filtration sufficient to add a significant fluid shear stress vector to BIFF is reached during limb movements capable of preventing blood pooling under gravity.

Evidence which supports a significant role of microcirculation in BIFF include: (1) Observations of IMP rise in response to muscle contraction have led to a proposal that leakage from medullary sinusoids can increase IMP enough to collapses both sinusoidal and continuous cap- 
illaries in the medullary canal — a classical Starling resister effect-resulting in both medullary and cortical ischemia (Otter et al., 1999). However, long periods of high IMP seem to occur only under pathological conditions such as ischemic osteonecrosis (Ficat and Arlet, 1980) and bone marrow edema syndrome (Jones, 1997). Although IMP is a poor indicator of blood flow in bone (Thomas et al., 1982; Bouteiller et al., 1984) the blood pressure changes associated with its increase are significant. (2) Blood flow to limb bones increases during exercise (Tondevold and Bulow, 1983). (3) Vascular resistance in limb bones increases during exercise (Gross et al., 1979). Observations 2 and 3 lead to the prediction of an increase in luminal (vessel) hydraulic pressure. However, measures of cortical vessel luminal pressure have not been reported, and even though blood is an incompressible fluid, it is non-Newtonian in small vessels and permeability of capillary walls is not uniformly distributed (Landis and Pappenheimer, 1963); consequently, neither is the transmural pressure gradient.

Absent direct measures of pressure in cortical vessels, one can detect effects of nutrient artery blood pressure changes and skeletal load changes in the medullary canal. For example, contraction of the quadriceps muscle causes a $30 \mathrm{mmHg}$ or more rise in femur IMP (MacPherson and Shaw, 1961; Shim et al., 1972; Kumar et al., 1979; Bryant, 1983). The contribution of femur bending to this value is not clear because the quadriceps complex was not released in the studies cited. Further, contributions of weight-bearing to IMP will vary if measures are obtained during walking. In humans IMP in the tibia has been measured to vary from $35 \mathrm{mmHg}$ in the supine to 46 mmHg during walking (McDermott et al., 1986). Interestingly, the corresponding standing pressures were about $85 \mathrm{mmHg}$ during weight-bearing (McDermott et al., 1986). Tibial IMP standing pressure in the goat is 15.5 mmHg (Welch et al., 1993), and serves as a caveat against extrapolating from quadripeds to bipeds. One must be careful to avoid extrapolation from IMP to BIFF in adjacent cortical bone. Correlation between IMP and cortical blood flow is poor ( Thomas et al., 1982; Bouteiller et al., 1984).

The muscle pump model does not preclude a direct effect of load on blood flow in bone. Non-oscillating static bending in the absence of muscle contraction reduces bone blood flow on the compression side and increases it on the tension side of a long bone (McDonald and Pitt Ford, 1993). Nor does the model preclude "crosstalk" between endothelial cells and bone cells via cytokines/ chemokines. Fluid shear stress on endothelial receptors upregulates their expression of peptides which stimulate bone cells (Guenther et al., 1986; MacIntyre et al., 1991; Alam et al., 1992; Tatrai et al., 1992; Oni et al., 1993; Petersen et al., 1993; Zaidi et al., 1993; Collin-Osdoby, 1994; Fiorelli et al., 1994; Kasten et al., 1994), and bone circulation is correlated with BMU work rate increase (Whiteside et al., 1977; Reeve et al., 1988;). Nor does it preclude possible contribution of sinusoidal marrow capillaries to the percolating fluid, which has been proposed to account for the rapid transport of large molecules through cortical bone (McCarthy and Yang, 1992). All of these effects must be coordinated in a total physiological model.

How convective are bone capillary filtration flows? How do flow rates reflect neighboring skeletal muscle activity? This is not known. McCarthy and Yang (1992) have attempted to set up a total transport model by superposing solutions to transport equations through (1) the capillary wall using the Renkin-Crone capillary permeability $(\mathrm{P})$-surface area $(\mathrm{S})$ product equation, $\mathrm{PS}=-\mathrm{Q} \ln (1-$ $\mathrm{E})$, where $\mathrm{Q}$ is blood volumetric flow rate and E extraction, (2) the extravascular space between capillary wall and osteon wall using Fick's second law, where the source concentration is determined by PS and (3) the bone matrix using a compartment diffusion model which attempted to include uptake of solutes by metabolizing bone cells. Transport in this model was considered to occur by diffusion and it allowed for high rates by arbitrarily increasing concentration gradients. When McCarthy (1997) attempted to account for transport of albumin by assuming diffusion in an in vivo experiment he found rates of transport so high that he had to conclude that the flow was convective. He doubted that cortical vessels were capable of such flow and proposed that the more permeable medullary sinusoids provided the logical pathway (McCarthy, 1997). However, it has been well established that similar continuous capillaries in other organs are capable of convective transmural transport (Nakamura and Wayland, 1975).

Nakamura and Wayland established a model to determine if macromolecular extravasation in mesentery was by diffusion or convection. Analyzing single vessels they reasoned that if the concentration gradient between a source (vessel center) and a sink (some point distance $\mathbf{x}$ from the vessel center) decreased its slope faster than the rate predicted for the molecule in question by Fick's second law, then the parsimonious conclusion was that the difference was convective transport. The gradient was represented by the ratio of concentrations at time $\mathrm{t}, \mathrm{C}_{\mathrm{x}}(\mathrm{x}, \mathrm{t}) /$ $\mathrm{C}_{0}(0, \mathrm{t})$, with $\mathrm{C}_{0}$ tending to be constant because the capillary was continuously perfused. In a given experiment with fluorescent macromolecules extravasating, concentration was directly proportional to fluorescence intensity, so the ratios were the same. Temporal change in concentration/fluorescence at $\mathbf{x}$ is predicted by equation (1) their error function form of Fick's law. Here D is the reference diffusion coefficient for the tested solute. A relative diffusion $\mathrm{D}^{*}$ is computed by replacing $\mathrm{C}_{\mathrm{x}} / \mathrm{C}_{0}$ with experimentally measured fluorescence intensity values. Where $\mathrm{D}^{*}>\mathrm{D}$, transport cannot be due to diffusion alone, and it is presumed that the amount of increase is a meas-

$$
\frac{C(x, t)}{C(0, t)}=\left(1+\frac{x^{2}}{2 D t}\right)\left[1-\frac{2}{\pi^{1 / 2}} \int_{o}^{x} e^{-t^{2}} d t\right] \frac{x}{(4 D t)^{1 / 2}}-\left(\frac{x e^{-\frac{x^{2}}{4 D t}}}{(\pi d t)^{1 / 2}}\right)
$$


Typical Line Scan for Control Group

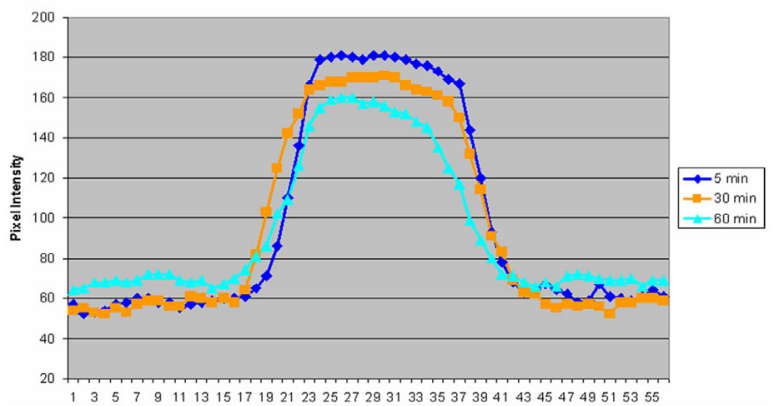

Typical Line Scan for Experimental Group

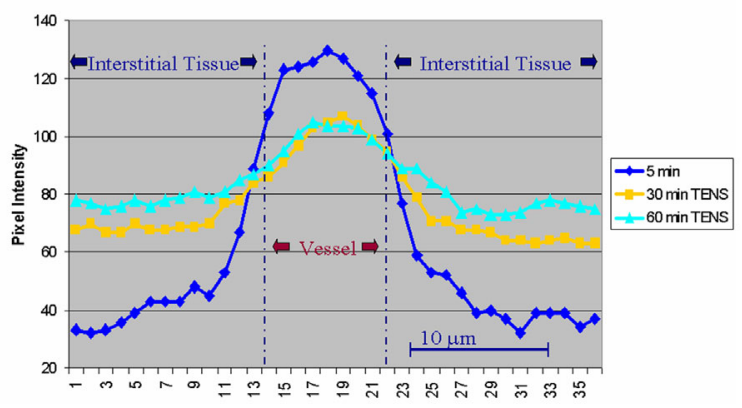

Figure 2. Effect of TENS on capillary filtration pre-and post 30 and 60 minutes stimulation. Peaks are dye in vessels.

ure of convection. Certainly, this measure will not be sufficient as a predictor of bone cell activating bone matrix percolation, but it will be necessary.

\section{Experiments Which Will Test the Model}

Verification of the model requires demonstration that increase in blood flow (which we have measured) is not compensated for by bone arteriolar constriction. Further, it must be shown that convective capillary filtration can occur in response to a muscle pump released from its tibial insert. Finally, it must be shown that extravascular flow generated by the muscle pump in the absence of poroelastic load is a significant component of (1) flow percolating through the lacunar-canalicular system and stimulating osteocytes and/or (2) perivascular flow stimulating osteoblasts and/or 3) perivascular flow stimulating osteoclasts. It would appear that the initial step in testing the model would be to determine if capillary filtration in cortical microvasculature (1) is convective or (2) can be made convective by the muscle pump. Preliminary data in support of this step have been obtained.

\section{Preliminary Data in Support of the Model}

Capillary filtration of large fluorescent molecules was used to indicate level of transport through large pores (assuming the two-pore model of Rippe and Haraldsson, 1994). Fluorescein isothiocyanate Dextran 70kDa (FITCD70) was injected into a rabbit and its entrance into cortical vessels in the compartment of an optical bone chamber implant (BCI) observed via intravital microscopy. Analysis of the recordings with an image processing program produced fluorescence intensity profiles across one vessel at three times. These results show an effect of muscle stimulation on capillary filtration. In previous work we have reported evidence that convective capillary filtration occurs in bone microvasculature without requiring muscle contraction (Winet and Bao, 1990). In this observation the ratio of change in intensity at a given distance $\mathbf{x}$ from the vessel was equivalent to the ratio of FITCD70 concentration change, $\mathrm{C}(\mathrm{x}, \mathrm{t}) / \mathrm{C}(0, \mathrm{t})$, at $\mathbf{x}$ over the same time period. Equation (1) was applied and compared with the same ratio for free diffusion of FITC-D70. For the profiles measured $\mathrm{D}^{*}>\mathrm{D}$ indicating that convection was indeed taking place.

Enhancement of capillary filtration in cortical bone by skeletal muscle contraction has also been tested. Figure 2 shows a comparison of two histograms of the fluorescence intensity incidence as a function of emission level. These data represent three vessels in a BCI compartment which is $2 \mathrm{~mm}$ in diameter and $100 \mu \mathrm{m}$ thick. FITC-D70 was injected before and RITC-D70 after 30 minutes of muscle stimulation. Stimulation came from a Tonatronic ${ }^{\hat{a}}$ model TMS DT 8000 transcutaneous electrostimulator applied externally over the gastrocnemius muscle. The TENS pattern was 30 volts at $80 \mathrm{~mA}$ and $4 \mathrm{~Hz}$. Absence of extravasation is normal for these large fluorescent molecules. Under TENS, however, capillary filtration is indicated by a rise in extravascular fluorescence. The $\mathrm{D}^{*}$ data and those in Figure 2 support the notion that convective capillary filtration is present in bone capillaries.

\section{Acknowledgements:}

This work was supported by the Los Angeles Orthopaedic Foundation, The Cora Kaiser Fund of Orthopaedic Hospital and the UCLA Department of Biomedical Engineering.

\section{References}

Alam AS, Huang CL, Blake DR, Zaidi M (1992) A hypothesis for the local control of osteoclast formation by $\mathrm{Ca}^{2+}$, nitric oxide and free radicals. Biosci Rep 12: 369380 .

Anderson JC, Eriksson C (1968) Electrical properties of wet collagen. Nature 218: 166-168.

Biot MA (1955) Theory of elasticity and consolidation for a porous anisotropic solid. J Appl Phys 26: 182185.

Björnberg J (1990) Forces involved in transcapillary fluid movement in exercising cat skeletal muscle. Acta Physiol Scand 140: 221-236.

Bouteiller G, Blasco A, Vigoni F, DéCamps JL (1984) The relationship between bone blood flows and intraosseous pressures. In: Bone Circulation. Arlet J, Ficat RP, Hungerford DS, (eds). Williams \& Wilkins, Baltimore. pp 371-374.

Bronk JT, Meadows TH, Kelly PJ (1993) The relationship of increased capillary filtration and bone forma- 
tion. Clinical Orthop 293: 338-345.

Bryant JD (1983) The effect of impact on the marrow pressure of long bones in vitro. J Biomechanics 16: 659665.

Burger EH. (2001) Experiments on cell mechanosensitivity: Bone cells as mechanical engineers. In: Bone Mechanics Handbook. Cowin SC (ed). CRC Press, New York. pp 21.21-21.27.

Chen AC, Nguyen TT, Shah RL (1997) Streaming potentials during the confined compression creep test of normal and proteoglycan-depleted cartilage. Ann Biomed Eng 25: 269-277.

Collin-Osdoby P (1994) Role of vascular endothelial cells in bone biology. J Cell Biochem 55: 304-309.

Cowin SC (1999) Bone poroelasticity. J Biomechanics 32: 217-238.

Cowin SC (2001a) Bone poroelasticity. In: Bone Mechanics Handbook. Cowin SC (ed), CRC Press, New York. pp 23.21-23.31.

Cowin SC (2001b) Estimate of relative osteogenic effect of simultaneous time varying mechanical loading and medullary pressure. In: Proceedings of the Third Bone Fluid Flow Workshop, Phoenix. Frangos JA (ed).(www.bonenet.net)

Davies PF (1995) Flow-mediated endothelial mechanotransduction. Physiol Rev 75: 519-560.

Dillaman RM. (1984) Movement of ferritin in the 2day-old chick femur. Anat Rec 209: 445-455.

Dillaman RM, Roer RD, Gay DM. (1991) Fluid movement in bone: Theoretical and empirical. J Biomechanics 24: 163-177.

Ficat RP, Arlet J (1980) Ischemia and Necrosis of Bone. Williams and Wilkins, Baltimore.

Fiorelli G, Orlando C, Benvenuti S, Franceschelli F, Bianchi S, Pioli P, Tanini A, Serio M, Bartucci F, Brandi ML (1994) Characterization, regulation and function of specific cell membrane receptors for insulin-like growth factor I on bone endothelial cells. J Bone Mineral Res 9: 329-337.

Frangos JA, Eskin SG, McIntire LV, Ives CL. (1985) Flow effects on prostacyclin production by cultured human endothelial cells. Science 227: 1477-1479

Fritton SP, McLeod KJ, Rubin CT. (2000) Quantifying the strain history of bone: Spatial uniformity and selfsimilarity of low-magnitude strains. J Biomechanics 33: 317-325.

Granger HJ, Laine GA, Green DM, Taber R (1981) Transport of water and solutes in the microcirculation. In: The Rheology of Blood. Blood Vessels and Associated Tissues. Gross DR Hwang NHC (ed). Sijthoff and Noordhoff, Rockville. pp 347-355

Greenleaf JE (1984) Physiological responses to prolonged bed rest and fluid immersion in humans. J Appl Physiol 57: 619-633.

Gross PM, Heistad DD, Marcus ML (1979) Neurohumeral regulation of blood flow to bones and marrow. Am J Physiol 237: H440-H448.

Guenther HL, Fleisch H, Sorgente N (1986) Endothelial cells in culture synthesize a potent bone cell active mitogen. Endocrinology 119: 193-201.

Hargens AR (1994) Recent bed rest results and coun- termeasure development at NASA. Acta Physiol Scand Suppl 616: 103-114.

Haskell A, Nadel ER, Stachenfeld NS, Nagashima K, Mack GW (1997) Transcapillary escape rate of albumin in humans during exercise-induced hypervolemia. J Appl Physiol 83: 407-413.

Hillsley MV, Frangos JA (1994) Review: Bone tissue engineering: The role of interstitial fluid flow. Biotechnol Bioeng 43: 573-581.

Hillsley MV, Frangos JA. (1997) Alkaline phosphatase in osteoblasts is down-regulated by pulsatile fluid flow. Calcif Tissue Int 60: 48-53.

Hung CT, Allen FD, Pollack SR, Brighton CT (1996) What is the role of the convective current density in the real-time calcium response of cultured bone cells to fluid flow? J Biomechanics 29: 1403-1409.

Johnson DL, McAllister TN, Frangos JA (1996) Fluid flow stimulates rapid and continuous release of nitric oxide in osteoblasts. Am J Physiol 271: E205-E208.

Jones JP (1997) Osteonecrosis and bone marrow edema syndrome: Similar etiology but a different pathogenesis. In: Osteonecrosis: Etiology, Diagnosis and Treatment. Urbaniak JR Jones JP (eds). American Academy of Orthopaedic Surgeons, Rosemont. pp 181-187.

Kajimura M, Head SD, Michel CC (1998) The effects of flow on the transport of potassium ions through the walls of single perfused frog mesenteric capillaries. J Physiol 511: 707-718.

Kasten TP, Collin-Osdoby P, Patel N, Osdoby P, Krukowski M, Misko TP, Settle SL, Currie MG, Nickols GA (1994) Potentiation of osteoclast bone-resorption activity by inhibition of nitric oxide synthase. Proc Natl Acad Sci USA 91: 3569-3573.

Keanini RG, Roer RD, Dillaman RM (1995) A theoretical model of circulatory interstitial fluid flow and species transport within porous cortical bone. J Biomechanics 28: 901-914.

Kelly PJ, Bronk JT (1990) Venous pressure and bone formation. Microvasc Res 39: 364-375.

Kelly PJ, Bronk JT (1994) Circulation, blood flow, and interstitial fluid flow in fracture healing. In: Bone Formation and Repair. Brighton CT, Friedlaender G, Lane JM (eds). American Academy of Orthopaedic Surgeons, Rosemont. pp 197-211.

Klein-Nuland J, Semeins CM, Ajubi NE, Nijweide PJ, Burger EH (1995) Pulsating fluid flow increases nitric oxide (NO) synthesis by osteocytes but not periosteal fibroblasts - Correlation with prostaglandin upregulation. Biochem Biophys Res Commun 217: 640-648.

Knothe Tate ML (2001) Interstitial fluid flow. In: Bone Mechanics Handbook. Cowin SC (ed). CRC Press, New York. pp 22.21-22.29.

Knothe Tate ML, Knothe U (2000) An ex vivo model to study transport processes and fluid flow in loaded bone. J Biomechanics 33: 247-254.

Knothe Tate ML, Niederer P, Knothe U (1998) In vivo tracer transport through the lacunocanicular system of rat bone in an environment devoid of mechanical loading. Bone 22: 107-117.

Knothe Tate ML, Steck R, Forwood MR, Niederer P (2000) In vivo demonstration of load-induced fluid flow 
in the rat tibia and its potential implications for processes associated with functional adaptation. J Exp Biol 203: 2737-2745.

Kumar S, Davis PR, Pickles B (1979) Bone-marrow pressure and bone strength. Acta Orthop Scand 50: 507512.

Landis EM, Pappenheimer JR (1963) Exchange of substances through the capillary walls. In: Handbook of Physiology, Section II, Circulation. Hamilton WF, Dow P (eds). American Physiological Society, Washington, DC. pp 9611034.

Li G, Bronk JT, An K-N, Kelly JP (1987) Permeability of cortical bone of canine tibia. Microvasc Res 34: $302-$ 310 .

Lipowsky HH. (1981) In vivo studies on the rheological behavior of blood flow in the microcirculation. In: The Rheology of Blood, Blood Vessels and Associated Tissues. Gross DR, Hwang NHC. (eds). Sijthoff \& Noordhoff, Rockville. pp 295-318.

MacGinitie LA, Stanley GD, Bieber WA, Wu DD (1997) Bone streaming potentials and currents depend on anatomical structure and loading orientation. J Biomechanics 30: 1133-1139.

MacGinitie LA, Wu DD, Cochran GVB (1993) Streaming potentials in healing, remodeling and intact cortical bone. J Bone Mineral Res 8: 1323-1335.

MacIntyre I, Zaidi M, Towhidul Alam ASM, Datta HK, Moonga BS, Lidbury PS, Hecker M, Vane JR (1991) Osteoclastic inhibition: An action of nitric oxide not mediated by cyclic GMP. Proc Natl Acad Sci USA 88: 29362940.

MacPherson A, Shaw NE (1961) Circulation of bone. Lancet 1:1285-1292.

Maspers M, Björnberg J, Mellander S (1990) Relation between capillary pressure and vascular tone over the range from maximum dilatation to maximum constriction in cat skeletal muscle. Acta Physiol Scand 140: 73-83.

Maspers M, Ekelund U, Björnberg J, Mellander S. (1991) Protective role of sympathetic nerve activity to exercising skeletal muscle in the regulation of capillary pressure and fluid filtration. Acta Physiol Scand 141: 351361.

McCarthy ID (1997) Clearance of albumin by cortical bone and marrow. Clin Orthop 334: 24-29.

McCarthy ID, Yang L (1992) A distributed model of exchange processes within the osteon. J Biomechanics 25: 441-450.

McDermott AG, Yabsley RH, Leahey JL (1986) A new method to measure intraosseous pressure. Clinical Orthop 208: 25-27.

McDonald F, Pitt Ford TR (1993) Blood flow changes in the tibia during external loading. J Orthop Res 11: 3648.

Michel CC, Curry FE (1999) Microvascular permeability. Physiol Rev 79: 703-761.

Miller BF, Gruben KG, Morgan BJ (2000) Circulatory responses to voluntary and electrically induced muscle contractions in humans. Phys Ther 80: 53-60.

Montgomery RJ, Sutker BD, Bronk JT, Smith SR, Kelly PJ (1988) Interstitial fluid flow in cortical bone.
Microvasc Res 35: 295-307.

Morris MA, Lopez-Curto JA, Hughes SPF, An K-N, Bassingthwaighte JB, Kelly PJ (1982) Fluid spaces in canine bone and marrow. Microvasc Res 23: 188-200.

Nakamura Y, Wayland H (1975) Macromolecular transport in the cat mesentery. Microvasc Res 9: 1-21.

Neglen P, Raju S (2000) Differences in pressures of the popliteal, long saphenous, and dorsal foot veins. J Vasc Surg 32: 894-901.

Ogunrinade O, Kameya GT, Truskey GA (2002) Effect of fluid shear stress on the permeability of the arterial endothelium. Ann Biomed Eng 30: 430-446.

Oni OOA, Dearing S, Pringle S (1993) Endothelial cells and bone cells. In: Bone Circulation and Vascularization in Normal and Pathological Conditions. Schoutens A, Arlet A, Gardeniers JWM, Hughes SP (eds). Plenum Press, New York. pp 43-48.

Otter M, Shoenung J, Williams WS (1985) Evidence for different sources of stress-generated potentials in wet and dry bone. J Orthop Res 3: 321-324.

Otter MW, Bronk JT, Wu DD, Bieber WA, Kelly PJ, Cochran GVB (1996) Inflatable brace-related streaming potentials in living canine tibias. Clinical Orthop 324: 283-291.

Otter MW, Palmieri VR, Cochran GVB (1990) Transcortical streaming potentials are generated by circulatory pressure gradients in living canine tibia. J Orthop Res 8: 119-126.

Otter MW, Palmieri VR, Wu DD, Seiz KG, MacGinitie LA, Cochran GVB (1992) A comparative analysis of streaming potentials in vivo and in vitro. $J$ Orthop Res 10: $710-719$.

Otter MW, Qin YX, Rubin CT, McLeod KJ. (1999) Does bone perfusion/reperfusion initiate bone remodeling and stress fracture syndrome? Med Hypotheses 53: 363368.

Petersen DN, Grasser WA, Thiede MA (1993) Rapid changes in the expression of vasoactive substances in nutrient blood vessels following immobilization precede a decline in bone marker gene expression in the tibia. Trans Soc Bone Mineral Res: 8: 5317

Petrov N, Pollack SR (2001) The idea that stress induced fluid flow can provide sufficient nutrient transport in osteons could be an illusion. In: Proceedings of the Third Bone Fluid Flow Workshop, Phoenix. Frangos JA (ed). (www.bonenet.net)

Piekarski K, Munro M (1977) Transport mechanism operating between blood supply and osteocytes in long bones. Nature 269: 80-82.

Pohl U, Holtz J, Busse R, Bassenge E (1986) Crucial role of endothelium in the vasodilator response to increased flow in vivo. Hypertension 8: 37-44.

Pollack SR. (2001) Streaming potentials in bone. In: Bone Mechanics Handbook. Cowin SC (ed). CRC Press, New York. pp 24.21-24.22.

Prendergast PJ, van der Meulen MCH (2001) Mechanics of bone regeneration. In: Bone Mechanics Handbook. Cowin SC (ed). CRC Press, New York. pp 32.31-32.13.

Qin Y-X, Lin W, Rubin C (2002) The pathway of bone fluid flow as defined by in vitro intramedullary pressure and streaming potential measurements. Ann Biomed Eng 


\section{0: 693-702.}

Reeve J, Arlot M, Wootton R, Edouard C, Tellez M, Hesp R, Green JR, Meunier PJ (1988) Skeletal blood flow, iliac histomorphometry, and strontium kinetics in osteoporosis: A relationship between blood flow and corrected appositional rate. J Clin Endocrinol Metab 66: 1124-1131.

Reich KM, Frangos JA (1991) Effect of flow on prostaglandin $\mathrm{E}_{2}$ and iositol triphosphate levels in osteoblasts. Am J Physiol 261: C428-C432.

Reich KM, Gay CV, Francos JA (1990) Fluid shear stress as a mediator of osteoblast cyclic adenosine monophosphate production. J Cell Physiol 143: 100-104.

Renkin EM, Tucker VL (1998) Measurement of microvascular transport parameters of macromolecules in tissues and organs of intact animals. Microcirculation 5: 139-152.

Rippe B, Haraldsson B (1994) Transport of macromolecules across microvascular walls: The two-pore theory Physiol Rev 74: 163-219.

Rubin C, Xu G, Judex S (2001) The anabolic activity of bone tissue, suppressed by disuse, is normalized by brief exposure to extremely low-magnitude mechanical stimuli. FASEB J 15: 2225-2229.

Saltin B, Rådegran G, Koskolou MD, Roach RC (1998) Skeletal muscle blood flow in humans and its regulation during exercise. Acta Physiol Scand 162: 421-436.

Sejersted OM, Hargens AR, Kardel KR, Blom P, Jensen O, Hermansen L (1984) Intramuscular fluid pressure during isometric contraction of human skeletal muscle. J Appl Physiol 56: 287-295.

Sejrsen P, Henriksen O, Paaske WP (1981) Effect of orthostatic blood pressure changes upon capillary filtration-absorption rate in the human calf. Acta Physiol Scand 111: $287-291$

Sexton WL (1995) Vascular adaptations in rat hindlimb skeletal muscle after voluntary running-wheel exercise. J Appl Physiol 79: 287-296.

Sexton WL, Korthuis RJ, Laughlin MH (1988) Highintensity exercise training increases vascular transport capacity of rat hindquarters. Am J Physiol 254: H274-H278.

Sexton WL, Laughlin MH (1994) Influence of endurance exercise training on distribution of vascular adaptations in rat skeletal muscle. Am J Physiol 266: H483H490.

Shim SS, Hawk HE, Wu WY (1972) The relationship between blood flow and bone marrow cavity pressure of bone. Surg Gynecol Obstetr 135: 353-360

Shiotani I, Sato H, Sato H, Yokoyama H, Ohnishi Y, Hishida E, Kinjo K, Nakatani D, Kuzuya T, Hori M (2002) Muscle pump-dependent self-perfusion mechanism in legs in normal subjects and patients with heart failure. J Appl Physiol 92: 1647-1654.

Shoemaker JK, McQuillan PM, Sinoway LI (1999) Upright posture reduces forearm blood flow early in exercise. Am J Physiol 276: R1434-R1442.

Shoemaker JK, Tschakovsky ME, Houghson RL.(1998) Vasodilation contributes to the rapid hyperemia with rhythmic contractions in humans. Can J Physiol Pharmacol 76: 418-427.

Sill HW, Chang YS, Artman JR, Frangos JA, Hollis TM, Tarbell JM (1995) Shear stress increases hydraulic conductivity of cultured endothelial monolayers. Am J Physiol 37: H535-H543.

Simkin PA, Huang A, Benedict RS (1990) Effects of exercise on blood flow to canine articular tissues. J Orthop Res 8: 297-303.

Slaaf DW, Oude Egbrink MGA (2002) Capillaries and flow redistribution play an important role in muscle blood flow reserve capacity. J Maladies Vasculaires 27: 63-67.

Spodaryk K, Dabrowski Z (1991) Blood flow in different regions of bone marrow after short term exercise. Acta Physiol Hung. 77: 13-17.

Srinivasan S, Gross TS (2000) Canalicular fluid flow induced by bending of long bone. Med Eng Phys 22: $127-$ 133.

Steck R, Niederer P, Knote Tate ML (2000) A finite difference model of load-induced fluid displacements within bone under mechanical loading. Med Eng Phys 22: 117-125.

Tarbell JM, Demaio ML, Zaw MM (1999) Effect of pressure on hydraulic conductivity of endothelial monolayers: The role of endothelial cleft shear stress. J Appl Physiol 87: 261-268.

Tatrai A, Lakatos P, Thompson S, Stern PH (1992) Effects of endothelin-1 on signal transduction in UMR106 osteoblastic cells. J Bone Mineral Res 7: 1201-1209.

Tondevold E, Bulow J. (1983) Bone blood flow in conscious dogs at rest and during exercise. Acta Orthop Scand 54: 53-57.

Thomas IH, Gregg PJ, Walder DN (1982) Intra-osseous phlebography and intramedullary pressure in the rabbit femur. J Bone Joint Surg Br 64: 239-242.

Turner CH, Forwood MR, Otter MW (1994) Mechanotransduction in bone: Do bone cells act as sensors of fluid flow? FASEB J 8: 875-878

Tzemos N, Lim PO, MacDonald TM. (2002) Is exercise blood pressure a marker of vascular endothelial function? Quart J Med 95: 423-429.

Walsh WR, Guzelsu N. (1991) Electrokinetic behavior of intact wet bone: Compartmental model. J Orthop Res 9: 683-692

Walsh WR, Guzelsu N (1993) Ion concentration effects on bone streaming potentials and zeta potentials. Biomaterials 14: 331-336.

Weinbaum S, Cowin SC, Zeng Y (1994) A model for the excitation of osteocytes by mechanical loading-induced bone fluid shear stresses. J Biomechanics 27: 339-360.

Welch RD, Johnston CEI, Waldron MJ, Poteet B (1993) Bone changes associated with intraosseous hypertension in the caprine tibia. J Bone Joint Surg 75A: 53-60.

Whiteside LA, Simmons DJ, Lesker PA (1977) Comparison of regional bone blood flow in areas with differing osteoblastic activity in the rabbit tibia. Clinical Orthop 124: $267-270$.

Williams DA (1999) Network assessment of capillary hydraulic conductivity after abrupt changes in fluid shear stress. Microvasc Res 57:107-117.

Winet H, Bao JY (1990) Relationship between volumetric flow and blood vessel dimensions in healing cortical bone. In: Engineering Science, Fluid Mechanics. Yates GT (ed). World Scientific, New York. pp 161-169.

Yuan Y, Granger HJ, Zawieja DC, Chilian WM (1992) 
Flow modulates coronary venular permeability by a nitric oxide related mechanism. Am J Physiol 263: H641-H646.

Zaidi M, Alam ASMT, Bax BE, Shankar VS, Bax CMR, Gill JS, Pazianas M, Huang CL-H, Sahinoglu T, Moonga BS, Stevens CR, Blake DR (1993) Role of endothelial cell in osteoclast control: New perspectives. Bone 14: 97-102.

\section{Discussion with Reviewers}

B. Noble: An important point that has not been addressed by the manuscript is that the authors' hypothesis could easily be tested directly by detaching muscles from major bone attachment points, stimulating them and measuring the osteogenic (load) response in the bone. In fact the opposite approach has already been undertaken, whereby the bones are loaded directly without any large degree of muscle activity (certainly not at the level associated with locomotory activity). I refer to the large amount of work undertaken by Lanyon, Clinton and the groups of Skerry and Mosley. These experiments clearly demonstrate that large scale muscle activity is not necessary for the classic bone response to loading to occur. These findings would seem to render the authors hypothesis less convincing.

Author: We have in fact tried that very experiment, releasing the peroneal muscle from the Achilles complex and found an increase in bloodflow, but the capillary filtration data were inconclusive due partly to a calibration error. We have taken care to point out in the ms that the proposed mechanism does not replace load. We think it is an expression of evolutionary redundancy wherein secondary mechanisms are recruited to assist primary ones when the latter are compromised. One circumstance where such compromise may occur is in microgravity.

D Jones: A theoretical mechanism is proposed, without any measurements, where muscle contractions increase the blood pressure and thus increase blood flow through the bone, leading to physiological responses. As pointed out at the time of the meeting by Brendon Noble, many animal experiments e.g. a very large series by Lanyon and nearly everyone else working in the field since then Rubin and others show that bone responds to loading without muscle working, by using external devices. The question therefore becomes a difficult one, can the Winet proposed mechanism contribute to the loading effect? Well, does my very high blood pressure lead to extra flow? No (blood vessels are not dilated so pressure goes up). So Winet's point is not very obvious - Why would fluid pushed around by the muscle go into a second organ? Surely it would go through the capillaries and back to the heart through the veins?

Using a wrist blood pressure monitor I can reproduce easily the effects of exercise on blood pressure so I assume intramuscular pressure is linked to this pressure in some way? Thus I see no reason to suppose the existence of a pump at all. What is the resistance of flow through the matrix? Very high, so flow is low.

Author: This model does not replace the poroelastic model, it complements it. All BIFF models accept that bone responds to loading because loading moves interstitial fluid, whether by bending its container (muscle load) or compressing its container (weight load). Blood is an incompressible fluid, marrow is not. When the vessel supplying the nutrient artery is compressed, pressure in the nutrient artery has no where to go but higher. This pressure will be passed on to nutrient artery branches until it is dissipated by wall friction or arteriolar smooth muscle contraction. We are not suggesting that the vessels supplying muscle feed bone (some which come through tendons do). We are saying that vessels feeding bone have to traverse compartments occupied by muscle. Their flow will be affected by muscle contraction.

D Jones: Diffusion? Knothe Tate and her colleagues calculate (personal communication) diffusion not using restricted volume models or thin tube models; hence the enhanced flow they see can well be enhanced diffusion taking this into account! Reflections of thermally driven molecules effectively increase the concentration many fold. Nakamura and Wayland (1975) didn't appreciate this. How does flow move in bone? Knothe Tate (again) shows only some compartments of bone showing enhanced dye penetration. Is this consistent with bone bending? And is it consistent with muscle pump?

Author: Please see Knothe Tate (2001) (text reference). She agrees that convective BIFF is necessary to explain her data. That there are compartmental differences is to be expected because osteon diameters vary with location in cortical bone as does incidence of microcracks and other structural characteristics. Nakamura and Wayland (1975) worked only with mesentery, giving a full account of the limits of their model. They had nothing to say about bone microcirculation, which was poorly understood then (It isn't that much better now.) In short, all recent data point to BIFF being convective. There can be no fluid shear stress without convective flow. The Weinbaum and Cowin (Weinbaum et al., 1994) poroelastic model would be irrelevant if this were untrue.

D Jones: Your hypothesis does not appear to account for the difference in pressure experiences when a person stands, surely to be consistent there should be some measurable rate of bone formation different from the head to the toes? Interestingly astronauts (based on very little data) appear to ADD bone to their skulls during spaceflight (perhaps a few percent only), due to an unknown mechanism. Do you think your hypothesis can account for this? Author: We share your concern about the lack of data showing significant cortical bone capillary filtration resulting from pure muscle contraction. We have seen, under conditions of muscle release (Achilles tendonotomy), sharp excursions of $1 \mu \mathrm{m}$ microspheres flowing in cortical vessels. In general, the microspheres reverse direction indicating a sudden reversal in pressure gradient in agreement with the hypothesis. You will note in the proposed hypothesis a caveat for insufficiency of isolated contractions of "twitch" magnitude. It is under exercise when such contractions are not only stronger and more regular, 
but the baseline blood pressure is higher due to increased heart rate. We are not in a position to test the hypothesis thus stated. The goal of my paper is not to confirm the hypothesis, but to propose it as reasonable given expected physiological conditions during a defined physiological state. The paper is being submitted to stimulate research in this area. Addition of the bioreactor to the model is done to show a practical consequence of the model, which follows from reasonable extrapolation. One can extrapolate a number of other consequences once the initial assumptions are accepted. As a first approximation, all modelling begins with this kind of approach. You will note that the hypothesis also suggests a treatment for microgravity osteopenia which does not require exercise and can be performed in spaceships. 